\title{
Role of dietary factors in management of cardiovascular diseases in rural population
}

\author{
Bhavani Yamasani $^{1}$, Siva Sakkara Reddy Pattubala $^{2}$, G. Raviprabhu ${ }^{3}$
}

\author{
${ }^{1}$ Department of Community Medicine, Sri Padmavathi Medical College (W), SVIMS, Tirupathi, Chittor, Andhra \\ Pradesh, India \\ ${ }^{2}$ Primary Health Centre, Chinnapandur, VaradaiahPalem, Chittor, Andhra Pradesh, India \\ ${ }^{3}$ Department of Community Medicine, ACSR Govt.Medical College, Nellore, Andhra Pradesh, India
}

Received: 09 June 2016

Accepted: 01 July 2016

\author{
*Correspondence: \\ Dr. Bhavani Yamasani, \\ E-mail: svims.faculty@gmail.com
}

Copyright: () the author(s), publisher and licensee Medip Academy. This is an open-access article distributed under the terms of the Creative Commons Attribution Non-Commercial License, which permits unrestricted non-commercial use, distribution, and reproduction in any medium, provided the original work is properly cited.

\begin{abstract}
Background: Management of cardiovascular diseases in relation to dietary factors presents a particular challenge due to the paucity of healthcare facilities and lack of awareness. Aim of the study the present study was undertaken to study the role of dietary factors in management of cardiovascular diseases.

Methods: A total of 734 respondents of both male and female subjects with age group of 30 years and above age group were taken consent to study the role of dietary factors in management of cardiovascular risk factors in rural population of Tirupati.

Results: The prevalence of low fruit and vegetable consumption has been found to be higher in those aged more than 50 years, female sex, Illiterate and primary level of education, unskilled occupation, unmarried/widowed/divorced, other religion, nuclear family, scheduled caste and tribe and those belonging to lower socioeconomic status. Extra salt consumption was found in $7.8 \%$ subjects. The cardiovascular risk was found $76 \%$ belong to low risk, and $9.8 \%$ to medium risk and $14.2 \%$ belong to high risk in our study.

Conclusions: The present study suggests that diet factors like fruit and vegetable intake, amount of salt and oil consumption are most important risk factors in managing the cardiovascular diseases.
\end{abstract}

Keywords: Cardiovascular, Diet, Factors

\section{INTRODUCTION}

Fruits and vegetables may promote cardiovascular health through a variety of micronutrients, antioxidants, phytochemicals, flavonoids, fibre and potassium. Cardio vascular disease risk score was inversely related to fruit and vegetable intake gram/day. The consumption of at least 400 grams of fruits and vegetables per day is recommended as a population intake goal to prevent diet related chronic diseases. ${ }^{1}$ Diet habitually high in salt intake play an important role in increasing blood pressure. Metabolic and epidemiological studies have indicated that trans-fatty acids increase the risk of coronary heart disease. ${ }^{2,3}$ Control of risk factors may be primary or secondary. Primary prevention implies control of risk factors before the onset of cardiovascular disease.

Secondary prevention denotes control of risk factors after the clinical setting of cardiovascular disease. ${ }^{4}$ Primary prevention is very important because $25 \%$ of patients may die even before they reach the doctor with the onset of cardiovascular disease. Most cost -effective approach to containing emerging epidemics of these diseases were to reduce the prevalence of these modifiable risk factors. ${ }^{5}$

The current study was undertaken to study the role of dietary factors in management of cardiovascular diseases. 


\section{METHODS}

We have selected both male and female subjects $(\mathrm{N}=734)$ with age group of 30 years and above age group to study the role of dietary factors in management of cardiovascular risk factors in rural area of Tirupati. Subjects were included in the cross-sectional study by using 20 cluster sampling technique. The study subjects were explained the purpose of the study and informed consent was taken from the subjects. One subject from each house aged 30 years and above is interviewed who is selected randomly from those available at home at the time of study. Ethical clearance for this study was accorded by Institutional ethical committee, Sri Venkateswara Medical College, Tirupati.

We have considered low fruit and vegetable intake as subjects who were taking less than three times per week latter was nondaily intake of vegetables. We have also considered percapita oil consumption was calculated by total oil intake by the family in a month divided by total number of family members excluding infants. We have considered socio-economic status, fruit and vegetable consumption, extra salt intake and cooking oil parameters to study the dietary factors prevalence in management of cardiovascular risk diseases.

Cardiovascular risk categorization was made as per American Heart Association, 2008 and recorded.

\section{RESULTS}

Most of the subjects are taking vegetables daily $(51.4 \%)$ or 3-4 times weekly (47.6\%). A majority of the subjects are taking fruits 3-4 times weekly $(56.0 \%)$. Extra salt consumption was found in $7.8 \%$ subjects (Table 1).It was found that around $92.5 \%$ of subjects are taking nonvegetarian foods. In a week time, chicken was taken by $90.7 \%$ subject, meat by $49.5 \%$ and fish by $32.8 \%$ subjects. Thus relatively chicken was the most common non-vegetarian food item and fish was the least common item consumed (Table 2). The commonest type of cooking oils consumed were palm oil $(58.7 \%)$, sunflower oil $(26.6 \%)$, and groundnut oil $(4.8 \%)$ in that order. As much as $9.9 \%$ subjects are taking a mixture of various oils for cooking purposes (Table 3 ).

The prevalence of low fruit consumption was found to be higher among those aged less than 50 years, female sex, those with illiteracy and primary level of education, unskilled occupation, unmarried/widowed/divorced, hindu religion, joint family, scheduled caste and tribe and those belonging to lower socioeconomic status. However only with regard to unskilled occupation, Scheduled caste and tribe and lower socioeconomic status, the differences were statistically significant (Table 4). It was found that the daily per-capita oil consumption was mostly between $25-50 \mathrm{ml}(72.9 \%)$ followed by less than $25 \mathrm{ml}(15.8 \%)$ while there was a proportion of $11.3 \%$ subjects who had per capita oil consumption of $50 \mathrm{ml}$ and above (Table 5).

Table 1: Details of dietary factors consumption $(n=734)$.

\begin{tabular}{|c|c|c|}
\hline Parameter & No. of subjects & Percentage \\
\hline \multicolumn{3}{|l|}{ Vegetable intake } \\
\hline (a) Daily & 377 & 51.4 \\
\hline $\begin{array}{l}3 \text { - } 4 \text { times } \\
\text { weekly }\end{array}$ & 350 & 47.6 \\
\hline $\begin{array}{l}\text { (c) } 1-2 \text { times } \\
\text { weekly }\end{array}$ & 7 & 1.0 \\
\hline \multicolumn{3}{|l|}{ Fruit intake } \\
\hline (a) Daily & 73 & 9.9 \\
\hline $\begin{array}{l}3 \text { - } 4 \text { times } \\
\text { weekly }\end{array}$ & 411 & 56.1 \\
\hline Weekly once & 106 & 14.4 \\
\hline Occasionally & 144 & 19.6 \\
\hline \multicolumn{3}{|l|}{ Extra salt } \\
\hline (a) Yes & 57 & 7.8 \\
\hline (b) $\mathrm{No}$ & 677 & 92.2 \\
\hline
\end{tabular}

Table 2: Non-vegetarian consumption and types of foods consumed $(\mathrm{N}=734)$.

\begin{tabular}{|c|c|c|}
\hline Parameter & No. of subjects & Percentage \\
\hline \multicolumn{3}{|c|}{ Non-vegetarian consumption } \\
\hline (a) Yes & 679 & 92.5 \\
\hline No & 55 & 7.5 \\
\hline \multicolumn{3}{|c|}{ Meat consumption (in a week) } \\
\hline (a) $\quad$ Yes & 363 & 49.5 \\
\hline (b) $\quad$ No & 371 & 50.5 \\
\hline \multicolumn{3}{|c|}{ Chicken consumption (in a week) } \\
\hline (a) $\quad$ Yes & 666 & 90.7 \\
\hline (b) $\quad$ No & 68 & 9.3 \\
\hline \multicolumn{3}{|c|}{ Fish consumption (in a week) } \\
\hline (a) $\quad$ Yes & 241 & 32.8 \\
\hline No & 493 & 67.2 \\
\hline
\end{tabular}


Table 3: Type of cooking oil used by subjects $(\mathrm{N}=734)$.

\begin{tabular}{|lll|}
\hline Type of Cooking oil & No. of subjects & Percentage \\
\hline Sunflower oil & 195 & 26.6 \\
\hline Groundnut oil & 35 & 4.8 \\
\hline Palm oil & 431 & 58.7 \\
\hline Gingelley oil & 3 & 0.4 \\
\hline Sunflower and Palm oil & 32 & 4.3 \\
\hline Sunflower and groundnut oil & 11 & 1.5 \\
\hline Sunflower and gingelly oil & 3 & 0.4 \\
\hline Groundnut and Palm oil & 14 & 1.9 \\
\hline Sunflower, Palm oil and groundnut oil & 10 & 1.4 \\
\hline
\end{tabular}

Table 4: Relationship between low fruit consumption (less than 3 times weekly) with certain socio-demographic factors $(n=734)$.

\begin{tabular}{|llll|}
\hline Factor & $\begin{array}{l}\text { Prevalence of Low fruit } \\
\text { intake }(\%)\end{array}$ & Odds ratio and 95\% CI & Statistical significance \\
\hline Age less than 50 years & $172 / 497(34.6)$ & $1.18(0.85-1.64)$ & $\chi 2=1.02 ; \mathrm{P}=0.31 ; \mathrm{NS}$ \\
\hline Female sex & $128 / 361(35.5)$ & $1.13(0.83-1.53)$ & $\chi^{2}=0.62 ; \mathrm{P}=0.43 ; \mathrm{NS}$ \\
\hline Illiterate \& Primary & $135 / 376(35.9)$ & $1.18(0.87-1.61)$ & $\chi 2=0.17 ; \mathrm{P}=0.27 ; \mathrm{NS}$ \\
\hline Unskilled occupation & $187 / 462(40.5)$ & $2.26(1.61-3.16)$ & $\chi 2=22.8 ; \mathrm{P}<0.001 ; \mathrm{S}$ \\
\hline Unmarried/widowed/divorced & $40 / 95(42.1)$ & $1.49(0.96-2.31)$ & $\chi^{2}=3.14 ; \mathrm{P}=0.07 ; \mathrm{NS}$ \\
\hline Hindu religion & $237 / 690(34.3)$ & $1.25(0.64-2.43)$ & $\chi^{2}=0.42 ; \mathrm{P}=0.51 ; \mathrm{NS}$ \\
\hline Joint family & $97 / 264(36.4)$ & $1.20(0.88-1.65)$ & $\chi^{2}=1.32 ; \mathrm{P}=0.25 ; \mathrm{NS}$ \\
\hline Scheduled caste \& tribe & $69 / 162(42.6)$ & $1.60(1.12-2.29)$ & $\chi 2=6.74 ; \mathrm{P}=0.009 ; \mathrm{NS}$ \\
\hline Low Socioeconomic status & $168 / 343(49.0)$ & $3.62(2.62-5.00)$ & $\chi 2=63.8 ; \mathrm{P}<0.001 ; \mathrm{S}$ \\
\hline
\end{tabular}

Table 5: Per capita oil consumption among the families.

\begin{tabular}{|lll|}
\hline Percapita oil consumption in $\mathrm{ml}$ & No. of subjects & Percentage \\
\hline Less than 25 & 116 & 15.8 \\
\hline $25-50$ & 535 & 72.9 \\
\hline 50 and above & 83 & 11.3 \\
\hline Total & 734 & 100.0 \\
\hline
\end{tabular}

Table 6: Mean Per-capita oil consumption by socioeconomic status.

\begin{tabular}{|c|c|c|c|}
\hline Variable & & Mean \pm SD & Statistical significance \\
\hline \multicolumn{4}{|c|}{ Socio-economic status } \\
\hline (a) & Upper \& Middle & $36.6 \pm 12.1$ & \multirow{2}{*}{$\mathrm{t}=4.06 ; \mathrm{P}<0.001 ; \mathrm{S}$} \\
\hline (b) & Lower & $34.8 \pm 11.5$ & \\
\hline \multicolumn{4}{|c|}{ Current Smoking } \\
\hline (a) & Yes & $35.8 \pm 12.9$ & \multirow[t]{2}{*}{$\mathrm{t}=0.78 ; \mathrm{P}=0.43 ; \mathrm{NS}$} \\
\hline (b) & No & $34.9 \pm 11.1$ & \\
\hline \multicolumn{4}{|c|}{ Current Alcohol intake } \\
\hline (a) & Yes & $36.9 \pm 12.4$ & \multirow[t]{2}{*}{$\mathrm{t}=2.25 ; \mathrm{P}=0.0026 ; \mathrm{S}$} \\
\hline (b) & No & $34.6 \pm 11.2$ & \\
\hline
\end{tabular}

Those with upper and middle socio-economic status had higher level of mean daily per capita oil consumption $(36.6 \mathrm{ml})$ than lower socio-economic class $(34.8 \mathrm{ml})$ and the difference is also found to be statistically significant $(\mathrm{P}<0.001 ; \mathrm{S})$. Similarly those who were taking alcohol currently had higher consumption $(36.9 \mathrm{ml})$ compared to those not taking alcohol (34.6) and the difference is also statistically significant $(\mathrm{P}=0.0026 ; \mathrm{S})$. Although a slightly higher level of consumption was found in smokers $(35.8$ $\mathrm{ml})$ compared to non-smokers $(34.9 \mathrm{ml})$, the difference is 
however not statistically significant $(\mathrm{P}=0.43$; NS). It was found that higher proportion of those belonging to unskilled occupations had been consuming $>35 \mathrm{ml}$ per capita oil daily (43.1\% compared to $29.4 \%$ and the difference is also found to be statistically significant $(\mathrm{P}<0.001 ; \mathrm{S})$ (Table 6).

Table 7: Relationship between low vegetable consumption (not daily) with certain socio-demographic factors $(\mathrm{N}=734)$.

\begin{tabular}{|c|c|c|c|}
\hline Factor & Low vegetable consumption $(\%)$ & Odds ratio and $95 \% \mathrm{CI}$ & Statistical significance \\
\hline Age 50 years and above & $127 / 237(53.6)$ & $1.34(0.98-1.83)$ & $\chi 2=3.43 ; \mathrm{P}=0.06 ; \mathrm{NS}$ \\
\hline Female sex & $178 / 361(49.3)$ & $1.05(0.79-1.41)$ & $\chi 2=0.13 ; \mathrm{P}=0.73 ; \mathrm{NS}$ \\
\hline Illiterate and Primary & 199 / $376(52.9)$ & $1.42(1.06-1.90)$ & $\chi 2=5.67 ; \mathrm{P}=0.02 ; \mathrm{NS}$ \\
\hline Unskilled occupation & $261 / 462(56.5)$ & $2.38(1.75-3.24)$ & $\chi 2=30.8 ; \mathrm{P}<0.001 ; \mathrm{S}$ \\
\hline $\begin{array}{l}\text { Unmarried/widowed/divo } \\
\text { rced }\end{array}$ & 47 / 95 (49.5) & $1.05(0.68-1.60)$ & $\chi^{2}=0.03 ; P=0.86 ; \mathrm{NS}$ \\
\hline Other religions & $23 / 44(52.3)$ & $1.17(0.63-2.15)$ & $\chi 2=0.25 ; \mathrm{P}=0.62 ; \mathrm{NS}$ \\
\hline Nuclear family & $235 / 470(50.0)$ & $1.16(0.86-1.57)$ & $\chi 2=0.97 ; \mathrm{P}=0.32 ; \mathrm{NS}$ \\
\hline Scheduled caste and tribe & $98 / 162(60.5)$ & $1.85(1.30-2.64)$ & $\chi 2=11.7 ; \mathrm{P}<0.001 ; \mathrm{S}$ \\
\hline $\begin{array}{l}\text { Low socio-economic } \\
\text { status }\end{array}$ & 225 / 343 (65.6) & $3.74(2.76-5.08)$ & $\chi 2=74.2 ; \mathrm{P}<0.001 ; \mathrm{S}-$ \\
\hline
\end{tabular}

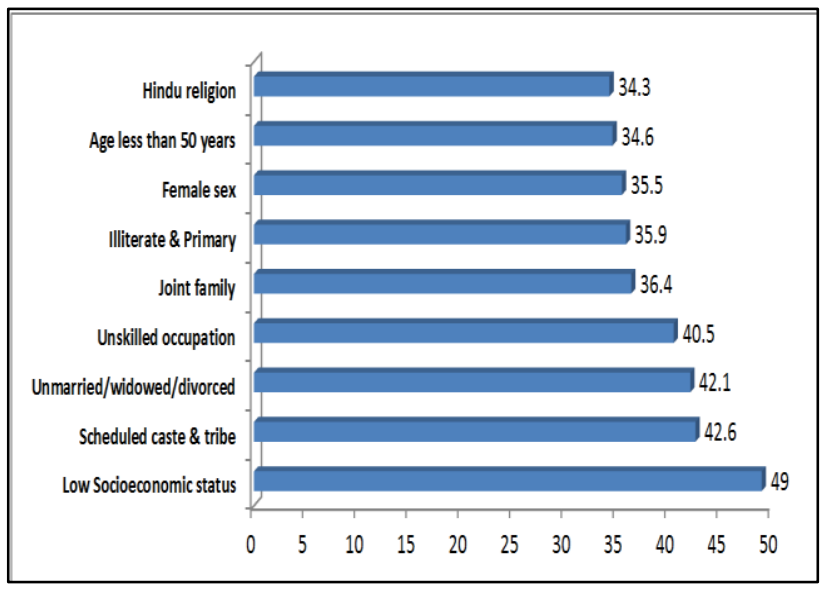

Figure 1: Relationship between low fruit consumption (less than 3 times weekly) with certain sociodemographic factors $(n=734)$.

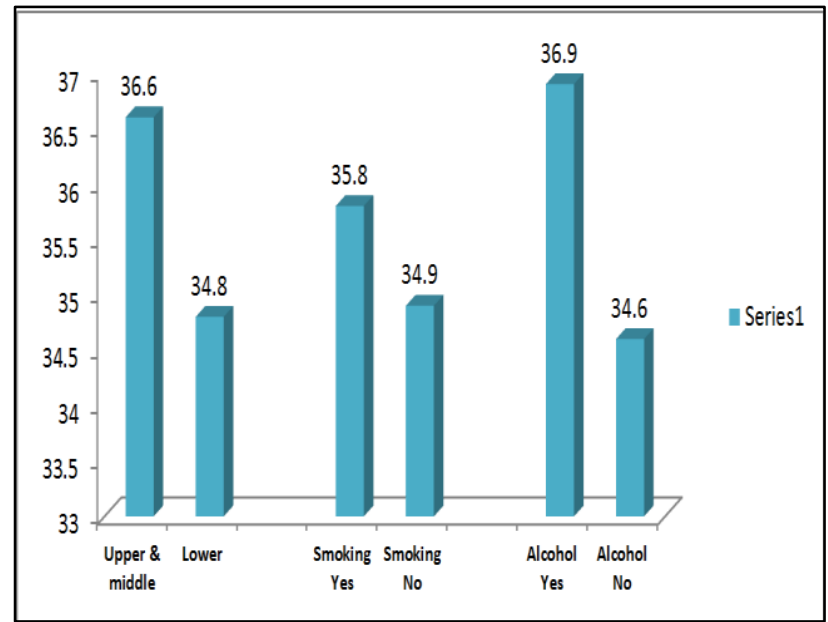

Figure 2: Mean Per-capita oil consumption by socioeconomic status.

Table 8: Cardiovascular risk categorization in the present study.

\begin{tabular}{|llll|}
\hline Cardiovascular risk category & Males $(\%)$ & Females $(\%)$ & Total $(\%)$ \\
\hline Low (less than $10 \%)$ & $217(58.5)$ & $341(94.4)$ & $558(76.0)$ \\
\hline Medium $(10-20 \%)$ & $58(15.5)$ & $14(3.9)$ & $72(9.8)$ \\
\hline High (Above 20\%) & $98(26.3)$ & $6(1.7)$ & $104(14.2)$ \\
\hline Total & $373(100.0)$ & $361(100.0)$ & $734(100.0)$ \\
\hline
\end{tabular}

$\chi 2=135.7 ; \mathrm{P}<0.001 ; \mathrm{S}$.

The prevalence of low vegetable consumption has been found to be higher in those aged more than 50 years, female sex, Illiterate and primary level of education, unskilled occupation, unmarried/widowed/divorced, other religion, nuclear family, scheduled caste and tribe and those belonging to lower socioeconomic status. However the differences were significant only with regard to 
unskilled occupation and lower socioeconomic status (Table 7). The cardiovascular risk was found $76 \%$ belong to low risk, and $9.8 \%$ to medium risk and $14.2 \%$ belong to high risk in our study (Table 8).

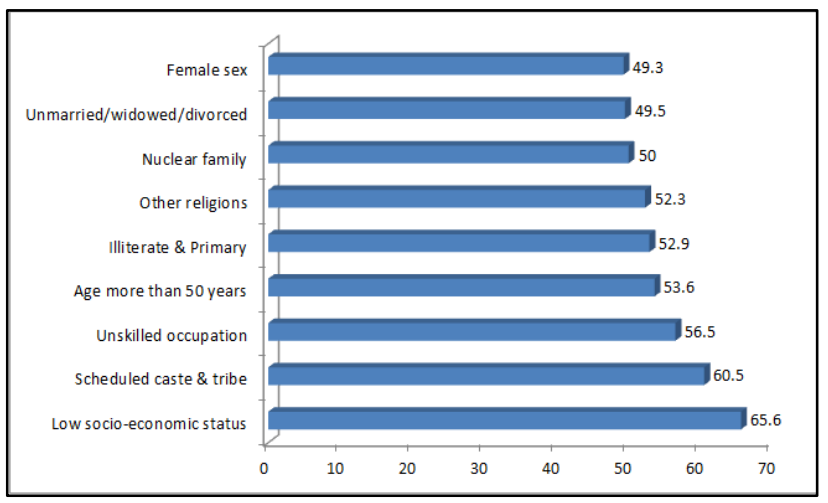

Table 7: Relationship between low vegetable consumption (not daily) with certain sociodemographic factors $(n=734)$.

\section{DISCUSSION}

The daily intake of vegetables was found in $51.4 \%$ subjects. It was found in the current study that a majority of them were taking fruits 3-4 times weekly $(56.0 \%)$. The extra salt consumption was found to be $7.8 \%$. A very high prevalence was reported in Assam study. ${ }^{6} \mathrm{~A}$ randomized controlled study has substantiated that sodium reduction may also reduce long-term risk of cardiovascular events. ${ }^{7}$ It was found in the present study that a large majority of them were non-vegetarians $(92.5 \%)$. It was found that the commonest cooking oil consumed were palm oil $(58.7 \%)$. It was sound that the daily per capita oil consumption was mostly between 25 $50 \mathrm{ml}(72.9 \%)$. The prevalence of low fruit consumption in the present study was found to be $34.0 \%$. A slightly higher level was found in a study in rural Karnataka study $42.8 \%{ }^{8}$ In the present study, low fruit consumption was found to be higher among those aged less than 50 years, female sex, those with illiteracy and primary level of education, unskilled occupation, unmarried/widowed/divorced, hindu religion, joint family, scheduled caste and tribe and those belonging to

lower socioeconomic status. However only with regard to unskilled occupation, scheduled caste and tribe and lower socioeconomic status, the differences were statistically significant. The low fruit consumption may be due to lack of awareness in the families regarding the nutritive value of seasonal and inexpensive fruits. A very high level was reported in rural Lucknow study $88.1 \%$. ${ }^{9}$ The prevalence of low vegetable consumption in the current study has been found to be $48.6 \%$. A low prevalence of $30.7 \%$ was reported in rural Karnataka study. ${ }^{8}$ In the present study, low vegetable intake was found to be higher in those aged more than 50 years, female sex, Illiterate and primary level of education, unskilled occupation, unmarried/widowed/divorced, other religion, nuclear family, scheduled caste and tribe and those belonging to lower socioeconomic status. However the differences were significant only with regard to unskilled occupation and lower socioeconomic status. Very high prevalence of $99.1 \%$ was reported in rural Lucknow. ${ }^{9}$ People with fruit and vegetable intake in the highest quintile had a relative risk for coronary heart disease of 0.80 (95\% CI 0.69 to 0.93 ) compared with those with intake in the lowest quintile. ${ }^{10}$ A Boston study evaluated the association between consumption of fruits and vegetables and risk of coronary heart disease in the Nurses' Health Study and the Health Professionals' Follow-Up Study. In these two studies, 84,251 women aged 34-59 years were followed for 14 years, and 42,148 men aged 40-75 years were followed for 8 years. All were free of diagnosed cardiovascular disease. ${ }^{11}$ A study in Cambridge, reviewed ecological, case-control and cohort studies examining the association of dietary fruits and vegetables with cardiovascular disease. For coronary heart disease, nine of ten ecological studies, two of three case-control studies and six of sixteen cohort studies found a significant protective association with consumption of fruits and vegetables or surrogate nutrients. ${ }^{12}$ For stroke, three of the five ecological studies and six of eight cohort studies found a significant protective association. ${ }^{11}$ For circulatory disease, one of two cohort studies reported a significant positive association. The cardiovascular risk estimated based on scoring recommended by American heart association has found that overall, $76 \%$ belong to low risk, and $9.8 \%$ to medium risk and $14.2 \%$ belong to high risk. The results of our study supports protective effect of fruits and vegetables on stroke and coronary heart disease. ${ }^{13}$

\section{CONCLUSION}

The present study suggests that diet factors like fruit and vegetable intake, amount of salt and oil consumption are most important risk factors in managing the cardiovascular diseases. Our study recommends that health awareness programmes should be conducted to promote the regular dietary intake of vegetables and seasonal and inexpensive fruits.

\section{ACKNOWLEDGEMENTS}

Authors acknowledge Faculty of Department of Community Medicine, SV Medical College, Tirupathi for their valuable suggestions during this work.

\section{Funding: No funding sources}

Conflict of interest: None declared

Ethical approval: The study was approved by the Institutional Ethics Committee

\section{REFERENCES}

1. Radhika G, Sudha V, Sathya RM, Ganesan A, Mohan V. Association of fruit and vegetable intake with cardiovascular risk factors in urban south 
Indians.British journal of Nutrition. 2008;99:398405.

2. $\mathrm{Hu}$ FB, Willett WC. Optimal diets for prevention of coronary heart disease. JAMA. 2002;27; 288(20):2569-78.

3. Pertinent P, Ascherio A, Korhonen P,Hartman AM, Willett WC,Albanes D et al. Intake of fatty acids and risk of coronary heart disease in a cohort of Finnish men. The Alpha-Tocopherol, Beta-Carotene Cancer Prevention Study. Am J Epidemiol. 1997; 145(10):876-87.

4. Yusuf S, Hawken S, Ounpuu S, Dans T, Avezum A,Hanas $\mathrm{F}$ et al. Effect of potentially modifiable risk factors associated with myocardial infarction in 52 countries: case-control study. Lancet. 2004;1117;364(9438):937-52.

5. Kumar NP, Shankaregowda HS, Revathy R. An assessment of preventable risk factors for chronic non-communicable diseases in an adult population, Asian J Epidemiology.2011;4(1):9-16.

6. Hazarika NC, Narain K, Biswas D, Kalita HC, Mahanta J. Hypertension in the native rural population of Assam. Natl Med J India. 2004;17(6):300-4.

7. Cook NR, Cutler JA, Obarzanek E, Buring JE, Rexrode KM, Kumanyika SK, et al. Long term effects of dietary sodium reduction on cardiovascular disease outcomes: observational follow-up of the trials of hypertension prevention. BMJ. 2007;334:885-8.
8. Dahal P, Venkataraman R, S Kumar BPS, Singh R, Tripathi P, Patel V. A study of socio-demographic and behavioral risk factor in patients with cardiovascular disease visiting rural hospital in south India. Int J Phar Sci Rev Res. 2013;22(2):1969.

9. Mahmood SE, Bhardwaj P, Srivastava JP, Mathur KP, Zaidi ZH, Shaifali I. Sociodemographic risk factors of cardiovascular disease in rural Lucknow Int J Med Pub health. 2012;2(1):56-61.

10. Liu S, Manson JE, Lee IM, Cole SR, Hennekens $\mathrm{CH}$, Willet WC, Buring JE, Fruit and vegetable intake of cardiovascular disease: the women's health study. Am J Clin Nutrit. 2000;72(4):899-900.

11. Joshipura KJ, Hu FB, Stampfer MJ, Manson JE, Rimm E,Speizer FE et al. The effect of fruit and vegetable intake on risk for coronary heart disease. Ann Intern Med. 2001;19;134(12):1106-14.

12. Ness AR, Powles JW. Fruit and vegetables, and cardiovascular disease: a review. Int J Epidemiol. 1997;26(1):1-13.

13. Hung HC, Joshipura KJ, Jiang R, Hu FB, Hunter $\mathrm{D}$, Smith Warner SA et al. Fruit and vegetable intake and risk of major chronic disease. J Natl Cancer Inst. 2004;96(21):1577-84.

Cite this article as: Yamasani B, Reddy Pattubala SS, Raviprabhu G. Role of dietary factors in management of cardiovascular diseases in rural population. Int $\mathbf{J}$ Community Med Public Health 2016;3:2174-9. 